\title{
A POSSÍVEL SOLUÇÃO JURÍDICA AO CONDOMÍNIO FECHADO: diálogo entre Direito das Coisas e Direito Urbanístico
}

\section{THE POSSIBLE JURIDICAL SOLUTION TO THE GATED COMMUNITY: dialog between Property Law and Urban Law}

\author{
LAHIS PASQUALI KURTZ \\ Acadêmica do Curso de Direito da Universidade Federal de Santa Maria \\ lahiskurtz@gmail.com
}

\begin{abstract}
RESUMO
0 presente artigo discute o crescente fenômeno de criação de condomínios fechados em áreas urbanas e as possíveis soluções jurídicas que são oferecidas pelo Direito Brasileiro a conflitos disso decorrentes. 0 tema foi abordado pelo método dialético combinado com o monográfico, para apresentar tanto pontos favoráveis à regularização deste instituto, o qual já existe de fato, quanto conflitos que podem decorrer de seu reconhecimento legal, em virtude da atribuição de responsabilidade sobre o planejamento urbano aos Municípios. Isso foi feito a partir de leitura e confronto entre as construções teóricas acerca do papel do condomínio fechado no contexto social e da sua regulamentação tanto sob a óptica do Direito Civil quanto do Direito Urbanístico. Concluiu-se pela incompatibilidade da atual situação do condomínio fechado com a regulamentação usada para legitimá-lo, o que aponta para urgência de adoção de medidas pela Administração Pública em buscar gerência desses espaços a fim de que cumpram com sua função social.
\end{abstract}

Palavras-chave: Condomínio fechado; Função social da propriedade; Limitação à propriedade; Planejamento urbano.

\begin{abstract}
The present paper discusses the growing phenomenom of creation of gated communities in urban areas and the possible juridical solutions which are offered by the Brazilian Law to the conflicts from it arised. The theme was addressed by the dialectic method combined with the monographic, so to present positive points about the regularization of this institute, which already exists in fact, as well as conflicts that can elapse from its legal recognition, due to the attribution of responsability for the urban planning to the counties. This was accomplished from reading and confrontation between the theoretical constructs around the role of the gated community in the social context and its regulation both from the perspective of the Civil Law and the Urban Law. It was concluded that the present situation of gated community is incongruent with the regulation used to legitimize it, what points to the urgency of the adoption of measures by the Public Administration thus puruiting the gerency of this places in order só that they accomplish their social function.
\end{abstract}

Keywords: Gated communities; Limitation to property; Social function of property; Urban planning.

\section{SUMÁRIO}

INTRODUÇAO; 1 ENTRE INTERESSES COLETIVOS E INTERESSES DE CLASSE: a legitimidade do condomínio fechado; 2 DENTRO DOS MUROS E FORA-DA-LEl: a natureza do Condomínio Fechado; 3 QUAIS SÃO AS SOLUÇÕES JURISPRUDENCIAIS?; CONCLUSÃO; REFERÊNCIAS. 


\section{INTRODUÇÃO}

Desde a antiguidade apresenta-se como elemento do desenvolvimento urbano a interação entre espaços públicos e espaços privados. As primeiras cidades originaram-se a partir da apropriação de territórios pelas famílias e da necessidade de administração coletiva dos demais territórios a fim de organizar a subsistência em local fixo. Esta é, até hoje, a lógica que orienta as cidades. Tem-se espaços pertencentes a indivíduos específicos e de ingerência extremamente restrita aos demais, ao lado de propriedades sobre as quais recai a administração do Poder Público, que se norteia pelos interesses da coletividade.

Há, no entanto, situações nas quais tal diferenciação entre o que deve ser administrado pelo Poder Público e o que pode pertencer à iniciativa privada não é tão clara, como é o caso dos chamados “condomínios fechados”. A resultar do salto de urbanização que se deu no Brasil entre os anos 1950 e 1970 observou-se o surgimento de tais formas de organização, que consistem em verdadeiros bairros, com várias edificações, ruas, iluminação, saneamento, praças, áreas de lazer, cuja administração e acesso é somente de seus moradores, que têm cada um fração ideal destas áreas comuns. Trata-se de grandes áreas de administração privada localizadas em espaço urbano, ligadas à rede de serviços públicos.

Diferentemente do desmembramento ou do loteamento comuns, no condomínio fechado há individualização somente de parte do território, sendo que as outras permanecem de uso coletivo dos proprietários, sem serem transferidas ao Poder Público. Porém, essas áreas seriam ruas, praças, espaços comuns com porte urbano, o que as tornaria assunto público. Ainda, há incerteza sobre a conformidade desta peculiar forma de propriedade quanto à regulamentação utilizada pela jurisprudência para justificá-la (art. $8^{\circ}$ da Lei 4.591/1964). Diante desta situação, aventa-se a necessidade de haver ingerência da Administração Pública (Município) no condomínio fechado, ao mesmo tempo que se questiona se isso é possível, eis que os institutos legais aparentam insuficiência.

Busca-se, com este trabalho, identificar possíveis problemas que surgem com a crescente presença desta realidade nos municípios brasileiros, e discutir as respostas oferecidas a eles pela limitação ao direito de propriedade e pela regulamentação urbanística. Para isso, utiliza-se método monográfico, através de uma abordagem dialética. Faz-se levantamento sobre as pesquisas que apontam as causas e consequências do fenômeno; também, examina-se o debate teórico envolvendo a natureza jurídica do condomínio fechado no ordenamento jurídico 
brasileiro, se sua regulamentação seria campo do direito público ou do privado. As construções teóricas serão ilustradas por meio de jurisprudências nas quais se discute cada uma das posições passíveis de aplicação, e as decisões serão criticamente analisadas a fim de se identificar quais as urgências que os conflitos envolvendo condomínios fechados trazem.

Para tanto, o trabalho está estruturado em três partes, sendo elas: 1) entre interesses coletivos e interesses de classe: a legitimidade do condomínio fechado; 2 ) dentro dos muros e fora-da-lei: a natureza do condomínio fechado e 3) juridicizar é a solução?, a partir das quais se apresentarão as considerações finais.

\section{ENTRE INTERESSES COLETIVOS E INTERESSES DE CLASSE: a legitimidade do condomínio fechado}

Desde sua origem, as cidades apresentam intrínseca relação com a apropriação de imóveis pelo homem, de maneira individualizada e em respeito a interesses privados. Esta forma de organização social tem suas primeiras manifestações registradas nas antigas Grécia e Roma, e guardam laços com a orientação religiosa das populações. No início da civilização, os antigos acreditavam que, uma vez enterrado um morto em determinado terreno, aquela propriedade passava ao domínio da família descendente, a qual tinha a obrigação de zelar por aquele espaço. Com isso, ficava proibido aos demais utilizarem aquela área. Com o tempo, os rituais passaram a abranger âmbito maior que o familiar, de maneira que cada família administrava o território que estava sob seu domínio, e conjuntamente com as outras famílias que habitavam em áreas próximas, administrava áreas que não estavam sob domínio de alguma família determinada, mas eram necessárias para o sustento de todas ${ }^{1}$.

O surgimento das cidades, em geral, resultou de modelos de organização coletiva e interação entre espaços públicos e privados, sendo que sobre os últimos era inexistente qualquer ingerência exterior ao círculo familiar; tal característica persiste na atualidade. No Direito brasileiro a legislação atenta para esta diferenciação, dando tratamento distinto a cada modalidade de domínio territorial.

A regulamentação do primeiro tipo de propriedade (privada) encontra-se principalmente no Código Civil, destinado a orientar as relações jurídicas entre particulares. Já o segundo tipo (pública) encontra-se regulamentado, quanto a seu uso e organização, nas normas de Direito

1 COULANGES, Fustel de. A cidade antiga. São Paulo: Martin Claret, 2002. 
Urbanístico; este ramo jurídico estabelece responsabilidades do Poder Público para garantia de direitos fundamentais que devem acompanhar a urbanização da sociedade.

É verdade que no Brasil, pela característica colonial que marcou parte importante de sua história e que ainda apresenta suas marcas, este modelo organizacional não decorreu de processo histórico em respeito a etapas. As cidades foram-se criando a partir de imposições oficiais, decorrentes de interesses das Metrópoles europeias ${ }^{2}$. À medida que se deu o crescimento desta maneira de organização ${ }^{3}$, aumentaram as responsabilidades dos administradores públicos; passou a haver obrigação destes em fornecer à população sob sua tutela determinadas garantias inerentes à vida urbana, as quais nem sempre foram atendidas conforme a demanda.

Resultado deste processo foi a cidade brasileira, na década de 90, ser “[...] associada à violência, poluição, criança desamparada, tráfego caótico - entre outros inúmeros males”, além de constatar-se que "[...] ao lado de intenso crescimento econômico, o processo de urbanização com crescimento da desigualdade resultou numa inédita e gigantesca concentração espacial da pobreza"4. Emergem nesta realidade as favelas e os loteamentos ilegais, construções habitacionais feitas na periferia da cidade, sem permissão dos proprietários dos terrenos e à revelia de regulamentações urbanas, geralmente por pessoas pertencentes à parcela da população que não possui outras condições de constituir habitação, dado o elevado preço de imóveis na área central urbana ${ }^{5}$.

Paradoxalmente, este mesmo fenômeno resultou em outra forma de organização urbana que também está à margem da Administração Pública, mas é de iniciativa da classe mais economicamente favorecida da população: grandes áreas residenciais, nos entornos ou em meio à área urbana, com construções de luxo e de acesso restrito, os condomínios fechados.

Este último fenômeno social, em que pese sua origem resultar do mesmo processo histórico das favelas, não pode ser equiparado a elas quanto à legitimidade. Desde o ponto de

2 SILVA, José Afonso da. Direito urbanístico brasileiro. 4. ed. São Paulo: Malheiros, 2006. p.21

3 "O Brasil chegou ao final do século XX como um país urbano: em 2000 a população urbana ultrapassou $2 / 3$ da população total, e atingiu a marca dos 138 milhões de pessoas. Este é o resultado de um processo iniciado na década de 50 na região Sudeste. A partir de então, este contraste se acentuou e se generalizou pelas cinco grandes regiões do país." IBGE teen. Características da população. Disponível em: <http://www.ibge.gov.br/ibgeteen/pesquisas/demograficas.html>. Acesso em: 28 nov. 2011.

4 SILVA, José Afonso da. Op. cit. pp. 22-23

5 ARANTES, Rafael de Aguiar. Qualidade de vida ou fortificações: o significado dos condomínios fechados em Salvador. In: Revista Veracidade, ano IV, $\mathrm{n}^{\circ}$ 4, março de 2009. Disponível em: <http://www.veracidade.salvador.ba.gov.br/v4/images/pdf/artigo3.pdf> Acesso em: 27 nov. 2011. p. 3 
vista do interesse da coletividade, o condomínio fechado representa um grande risco, enquanto que as favelas representam o suprimento de uma urgência não atendida pelo Poder Público.

O loteamento irregular é fundamentado no direito à moradia e consiste em autotutela de parte da população à qual esta garantia constitucional ${ }^{6}$ é inacessível de outra maneira. Já no caso do condomínio fechado, ocorre constituição de propriedade privada sobre grande área urbana, envolvendo áreas que seriam de uso público num loteamento normal mas que são mantidas privativas, com fulcro na sensação de inefetividade da segurança pública ${ }^{7}$.

A iniciativa privada assume, neste último caso, funções cuja responsabilidade é da Administração Pública, tais como policiamento e construção viária, e clama para si o uso e a administração dos espaços por ela ocupados. Cria-se espaço privado que propõe lógica diversa da que norteia as cidades, rompe com qualquer interação entre público e privado. Os moradores desses locais ligam-se a toda a estrutura urbana, utilizando-a quando necessário, mas não permitem que os cidadãos externos ao condomínio usufruam da estrutura dos espaços comuns da área fechada. É uma propriedade que se volta unicamente ao conforto de seus titulares, embora tenha dimensões que comportam estrutura urbanizada.

Sob o ponto de vista do Direito Civil, a partir de sua interpretação à luz da Constituição Federal Brasileira de 1988, tem-se a atribuição, a todos os direitos, de uma função social. É por isso que há limitações, em favor do interesse público ou coletivo, ao direito de propriedade, não mais visto com caráter absoluto, como era classificado antes da adoção de princípios constitucionais para leitura da lei civil ${ }^{8}$. Assim, a criação de espaços privados de grandes dimensões não pode se pautar em interesses privados, deve também respeitar a lógica da coletividade.

O que se oberva no caso dos condomínios fechados é o argumento da insuficiência da segurança pública, que tornaria impossível viver com tranquilidade numa comunidade ampla. Se observado à luz da função social, o fundamento apresentado para os condomínios fechados é questionável. Sua primeira fragilidade é que aponta para a ideia de "medo da violência". Esse

\footnotetext{
6 "Art. $6^{\circ}$ São direitos sociais a educação, a saúde, a alimentação, o trabalho, a moradia, o lazer, a segurança, a previdência social, a proteção à maternidade e à infância, a assistência aos desamparados, na forma desta Constituição. [grifo meu]" BRASIL. Constituição Federal. Brasília: Senado Federal, 1988. Disponível em: <http://www.planalto.gov.br/ccivil_03/constituicao/constitui\%C3\%A7ao.htm> Acesso em: 1 dez. 2011

7 MUKAI, Toshio. Temas atuais de direito urbanístico e ambiental. Belo Horizonte: Fórum, 2004. p. 134

8 RIZZARDO, Arnaldo. Direito das coisas: Lei $n^{\circ} 10.406$, de 10.01.2002. 2. ed. Rio de Janeiro: Forense, 2006. p. 58
} 
elemento, o medo, tem, conforme estudos ${ }^{9}$, grande influência no comportamento social; porém, nem sempre ele é realmente baseado no real aumento da criminalidade. Isso significa que a população, mesmo sem realmente vivenciar a suposta insuficiência da segurança pública, acredita estar em risco, e aposta na segregação em pequenos grupos que mantenham sua própria segurança de maneira privada.

Além disso, aponta-se para fato de que essa forma de propriedade sectariza uma parte específica da população, delimitando que somente ela terá acesso a determinada área. Depreende-se daí o perigo de haver perda da pluralidade ao se permitir agrupar partes da população em parcelas homogêneas, territorializando as classes sociais.

Os indivíduos de classes menos favorecidas, ao serem confinados a determinadas trajetórias que não podem estar inseridas no espaço dos condomínios, têm seu espaço urbano reduzido. Além disso, quem tem acesso aos benefícios do interior do condomínio não tem grande interesse em reclamar melhores políticas públicas para os espaços que estão no exterior, eis que não os utiliza tanto quanto os demais cidadãos.

Esta possibilidade esvazia os espaços públicos, de construção coletiva, empobrece a realidade cultural das cidades e, em casos extremos, submeteria a população a interesses não públicos, mas aos particulares, de determinados segmentos da população ${ }^{10}$. Esses elementos fáticos indicam reflexos sociais que têm relevância jurídica. Na medida em que é aplicado um instituto legal que afaste a ingerência pública desses espaços, pode-se ferir direitos sociais caros à democracia. A extratificação econômica da sociedade vai de encontro à igualdade e à dignidade da pessoa humana.

Constatações como estas apontam para a necessidade de reflexão sobre as consequências deste fenômeno, para ir além do reconhecimento do condomínio fechado como realidade e constatar também o que decorre desta situação. É certo que toca ao direito oferecer uma resposta aos conflitos que daí se apresentam. Cabe, então, como próximo ponto, atentar para a caracterização do condomínio fechado no direito brasileiro, tanto nas leis quanto na jurisprudência.

\footnotetext{
9 AMENDOLA, Giandomenico. La ciudad postmoderna magia e miedo de la metrópolis contemporánea. Madri: Celeste Ediciones, 2000. apud ARANTES, Rafael de Aguiar. Qualidade de vida ou fortificações: o significado dos condomínios fechados em Salvador. In: Revista Veracidade, ano IV, nº 4, março de 2009. Disponível em: <http://www.veracidade.salvador.ba.gov.br/v4/images/pdf/artigo3.pdf> Acesso em: 27 nov. 2011. p 6

10 Ibidem. p. 5
} 


\section{DENTRO DOS MUROS E FORA-DA-LEI: a natureza do Condomínio}

\section{Fechado}

O Código Civil estabelece, para os diferentes jeitos de uso de bens, consequências jurídicas, regras quanto ao que ocorre em cada caso. Devido à nomeação empregada para o condomínio fechado cotidianamente, tende-se a pensar neste como maneira de condomínio. Nessa figura jurídica vários proprietários têm o domínio de uma fração ideal, ou de partes discriminada e ideal, de uma coisa não dividida - geralmente um imóvel.

De maneira análoga, pretende-se que o condomínio fechado seja concebido como formado por unidades imobiliárias individualizadas pertencentes a condôminos específicos - as casas ou edificações - e áreas comuns - praças, ruas, salão de festas, piscina, etc - das quais cada condômino possui uma fração ideal. Tal classificação aproxima-o da figura do condomínio edilício. Esse instituto é previsto pelo artigo 1.331, $\$ 3^{\circ}$, do Código Civil: “ $\$ 3^{\circ} \mathrm{A}$ cada unidade imobiliária caberá, como parte inseparável, uma fração ideal no solo e nas outras partes comuns, que será identificada em forma decimal ou ordinária no instrumento de instituição do condomínio. (Redação dada pela Lei n 10.931, de 2004)"11.

Porém, o Código Civil silencia a respeito de casos nos quais haja mais de uma edificação envolvida, que é o caso dos condomínios fechados. Por isso, a fundamentação jurídica a que se recorre é a Lei $n^{\circ} 4.591$ de 1964, sobre o condomínio em edificações e incorporações imobiliárias. Em seu artigo $8^{\circ}$, caput, essa norma dispõe: “Quando, em terreno onde não houver edificação, o proprietário, o promitente comprador, o cessionário deste ou o promitente cessionário sobre ele desejar erigir mais de uma edificação, observar-se-á também o seguinte”, e determina que "[...] serão discriminadas as partes do total do terreno que poderão ser utilizadas em comum pelos titulares de direito sobre os vários tipos de unidades autônomas" e “[...] serão discriminadas as áreas que se constituírem em passagem comum para as vias públicas ou para as unidades entre si"12.

\footnotetext{
${ }^{11}$ BRASIL. Lei $n^{\circ} 10.406$ de 10 de janeiro de 2002. Institui o Código Civil. In: Diário Oficial da República Federativa do Brasil. Brasília, DF, 11 jan. 2002. Disponível em: <http://www.planalto.gov.br/ccivil_03/leis/2002/L10406.htm>. Acesso em: 1 dez. 2011.

${ }^{12}$ BRASIL. Lei n ${ }^{\circ} 4.591$ de 16 de dezembro de 1964. Dispõe sobre o condomínio em edificações e as incorporações imobiliárias. In: Diário Oficial da República Federativa do Brasil. Brasília, DF, 21 dez. 1964. Disponível em: <http://www010.dataprev.gov.br/sislex/paginas/42/1964/4591.htm>. Acesso em: 1 dez. 2011.
} 
Conforme depreende-se do último trecho desse artigo da lei mencionada, fica claro que a regulamentação ali prevista é para casos nos quais as edificações serão feitas no meio de um quarteirão, sem acesso à rua. Por isso, prevê que para tanto se faz necessário construir via própria, que leva somente da rua aos edifícios, ou de um edifício a outro, mas não constitui caminho para outros locais, como áreas comuns construídas. Perante esse conjunto de fatos, a lei determina que a rua, nesse caso, permanece de acesso restrito ${ }^{13}$.

A individualização de partes de um terreno para edificá-las, construindo ruas e rede elétrica e de saneamento é, na prática, mais semelhante à figura do loteamento. Nesse caso, porém, as ruas passam ao Poder Público, não se constitui maneira privada de administração. Restringir acesso a verdadeira rede viária interna de área extensa o suficiente para constituir um bairro, mantendo-a em poder de particulares, é questão que vai além do Direito Civil. Por envolver desenvolvimento urbano e ordenação do solo, coloca-se como questão de Direito Urbanístico $^{14}$.

Sendo assim, o condomínio fechado - ou lotemento fechado, como é chamado em algumas obras ${ }^{15}$ - é maneira incidental de organização da propriedade, não abarcada pelas previsões legais. Diz a doutrina que, juridicamente, “[...] os tais loteamentos fechados não existem"16, que "não se reconhece o condomínio quando muito extensa a área subdividida e alienada em partes autônomas", "se o complexo de residências resultar em um novo aglomerado de cidade, com extensas vias [...] não pode ser registrado na forma de condomínio"17.

O que ocorre na realidade, a despeito disso, é a proliferação desta maneira de organização habitacional, cujas obras são de custo vultoso. Uma vez concluídas, passam a gerar problemas à administração municipal. Isso acontece tanto (a) pela ausência de planejamento prévio sobre o impacto urbano que aquele empreendimento terá no local onde for realizado mudanças no trânsito, no escoamento de água e esgoto, na segurança, no comércio - quanto (b) pela possibilidade da administração privada não ser suficiente para mantê-lo.

\footnotetext{
${ }^{13}$ RIZZARDO, Arnaldo. Direito das coisas: Lei $n^{\circ} 10.406$, de 10.01.2002. 2. ed. Rio de Janeiro: Forense, 2006. p. 654

${ }^{14}$ SILVA, José Afonso da. Direito urbanístico brasileiro. 4. ed. São Paulo: Malheiros, 2006. p. 352

${ }^{15}$ MUKAI, Toshio. Temas atuais de direito urbanístico e ambiental. Belo Horizonte: Fórum, 2004. SILVA, José Afonso da. Op. cit.

${ }^{16}$ SILVA, José Afonso da. Op. cit.. p. 352

${ }^{17}$ RIZZARDO, Arnaldo. Op. cit. p. 656
} 
Neste último caso, o que era antes visto como bem particular, pertencente e restrito ao condomínio, tal como arruamento, praças, serviços coletivos, passa a ser apresentado ao Poder Público como sua responsabilidade ${ }^{18}$.

Chegam ao Poder Judiciário demandas apresentando problemas quanto a esta figura para as quais não se tem solução jurídica específica, como se verá a seguir.

\section{QUAIS SÃO OS TRATAMENTOS JURISPRUDENCIAIS?}

Frente à ausência de certeza sobre a regularidade ou não dos condomínios fechados, apresentam-se demandas relativas a atos de ingerência administrativa sobre eles. 0 Judiciário oscila entre três entendimentos: (i) reconhecer natureza privada (fundamentando-se na legislação civilista acima referida) a esses espaços, (ii) considerá-los de natureza urbana (fundamentando-se nas leis urbanísticas), e (iii) ainda, há um terceiro e interessante caso misto.

No segundo caso, o reconhecimento da natureza urbana leva à publicização, eliminando a ideia de um amplo espaço privado, o que descaracteriza o condomínio como tal e leva-o a uma concepção de loteamento que necessita ser retornado ao Poder Público.

O terceiro caso é exemplificado jurisprudencialmente, em decisão de segunda instância, natureza pública aos espaços comuns, porém é permitida a concessão aos condôminos, pelo gestor público, de serviços como conservação e segurança, sem exclusividade e desde que respeite o direito de ir e vir. Os proprietários recorreram ao Superior Tribunal de Justiça da decisão para garantir que, por cautela, ficasse suspenso o efeito da sentença para que não fossem demolidas estruturas que barravam o acesso de terceiros ao condomínio fechado.

A fim de ilustrar os fundamentos e as consequências de cada tipo de entendimento, a seguir tem-se trechos de decisões. Mas já de início vale ressaltar que, se fosse elaborada lei para que o condomínio fechado tal como se apresenta fosse considerado de caráter privado, tal figura seria mais restritiva quanto a atos administrativos, o que não ocorre quando é reconhecida a natureza urbanística desta forma de organização. As criações jurisprudenciais, nesse sentido, trarão as duas realidades e, ainda, abrem caminho para uma terceira via.

Existe decisão de viés privativista, reconhecendo legitimidade ao Município para conceder à iniciativa privada a gerência sobre deveres públicos, tal como a segurança, o que é constatado neste acórdão de Órgão Especial do Tribunal de Justiça do Estado de São Paulo, na

\footnotetext{
${ }^{18}$ SILVA, José Afonso da. Op. cit. p. 354
} 
Ação Direta de Inconstitucionalidade $n^{\circ}$ 68.759-0/0, julgada em 2001, quanto a lei municipal que autorizou fechamento de lotementos, decidindo pela constitucionalidade:

[...] a violência é mal gravíssimo que aflige principalmente a classe média que paga a maior parte dos impostos e não a [sic] segurança garantida com eficiência pelo Poder Público. Não se trata de delegar aos particulares atribuição que não lhes é própria, inerente ao campo da segurança pública, mas permitir-lhes que possam proteger-se, através de meios necessários, uma vez que o Poder Público, nesse aspecto, tem sido ineficiente.

Destarte, se o município tem competência para disciplinar a matéria observada a lei local, inegável que, na espécie, não se verifica a alegada inconstitucionalidade. ${ }^{19}$

Essa decisão utiliza-se do argumento das competências legislativas do Município. Ainda que realmente haja competência do Município para legislar sobre esta matéria, retoma-se como contraponto a limitação dos direitos patrimoniais à sua função social. Que função social poderia haver em proteger uma parte da população, economicamente favorecida, da violência urbana, restringindo acesso dos demais habitantes a parte da cidade? Mais interessante apresenta-se a proposta de arrecadação de espaços privatizados indevidamente e o retorno de sua administração ao gestor público, tendo em vista a garantia do interesse público. Posterior ou simultaneamente, poderia-se adotar políticas públicas ou público-privadas de segurança.

Ademais, deve-se ressaltar que a competência do Estado para prestação de segurança é absoluta, não pode ser delegada a terceiros. Assim, por mais que o Município permita por lei que outros entes, privados, realizem fechamento de área com dimensões urbanas, a fim de garantir sua segurança, essa determinação legal esbarra na função social da propriedade, constitucionalmente estabelecida, e foge ao interesse público.

Há decisão do Superior Tribunal de Justiça neste sentido, não reconhecendo o conjunto (ruas e edificações) como figura jurídica legítima. Isso é corroborado pelo seguinte acórdão, que admite a publicização de rua que pertencia a condomínio:

PROCESSUAL CIVIL E ADMINISTRATIVO. CONDOMÍNIO. LOGRADOURO PÚBLICO. RECONHECIMENTO. COMPETÊNCIA DA CÂMARA DE VEREADORES. ACÓRDÃO RECORRIDO ADEQUADAMENTE FUNDAMENTADO. LEI MUNICIPAL 3.317/2001. VALIDADE. LEI 6.766/1979. BEM DE USO COMUM DO POVO.

1. Discute-se a validade da Lei Municipal 3.317/2001, que reconheceu como logradouro público (e nomeou) via que, segundo o impetrante, é particular, pois pertencente a condomínio fechado (vila).

\footnotetext{
${ }^{19}$ MUKAI, Toshio. Temas atuais de direito urbanístico e ambiental. Belo Horizonte: Fórum, 2004. p. 141
} 
2. A discussão destes autos reflete a triste realidade das cidades brasileiras, em que os moradores isolam-se por medo, não apenas em suas casas, mas também fechando vias de acesso, como as de condomínios.

3. In casu, as denominadas "ruas particulares internas do condomínio" são, em verdade, vias asfaltadas, com meio-fio, sarjetas, postes de iluminação, rede aérea de energia elétrica e tráfego de veículos automotores, em nada lembrando veredas para pedestres, como as que existem em tantos condomínios edilícios. Os imóveis lá localizados constituem pequenos sobrados, murados e com portões. No início da rua principal, há grade metálica guardada por seguranças particulares.

[...]

6. O reconhecimento de logradouros públicos é competência municipal, em face de nítido interesse local, nos termos do art. 30, I, da Constituição Federal.

7. $O$ argumento do impetrante, de que a Lei 3.317/2001 (que admitiu a via como pública) ofenderia a legislação local (Lei 2.645/1998 e Decretos do Executivo), carece de fundamento lógico- jurídico.

8. O Legislativo, pela lei anterior (Lei 2.645/1998), delimitou a atuação do Executivo no que se refere ao reconhecimento de logradouros. Impossível interpretá-la como norma que restrinja a competência legislativa da Câmara.

9. A competência legislativa municipal é fixada diretamente pela Constituição Federal $($ art. 30, I) e não pode ser reduzida, alterada ou extinta por lei local. A Lei 3.317/2001, combatida pelo impetrante, representa o exercício da competência legislativa pela Câmara em relação a um caso concreto e não se submete a norma anterior de mesma hierarquia.

10. A natureza pública ou privada de logradouro urbano não depende apenas da vontade dos moradores. No momento em que o particular parcela seu imóvel e corta vias de acesso aos diversos lotes, o sistema viário para circulação de automóveis insere-se compulsoriamente na malha urbana. 0 que era privado torna-se parcialmente público, uma vez que os logradouros necessários ao trânsito dos moradores são afetados ao uso comum do povo (art. $4^{\circ}$, I e IV, da Lei 6.766/1979).

11. A Municipalidade é senhora da necessidade de afetação dos logradouros ao uso público, para, então, declará-los como tal. No caso dos autos, esse reconhecimento pelo Legislativo é evidentemente adequado.

12. Embora compreensível a preocupação dos moradores com sua segurança, sentimento compartilhado por todos os que vivem nos grandes (e cada vez mais também nos médios e até pequenos) centros urbanos brasileiros, não se coloca, no nosso Direito, a possibilidade de formação de comunidades imunes à ação do Poder Público e às normas urbanísticas que organizam a convivência solidária e garantem a sustentabilidade da Cidade, para as presentes e futuras gerações.

13. Ademais, a argumentação relativa à segurança dos moradores é, na presente demanda, desprovida de relação direta com a medida impugnada. Isso porque o reconhecimento da natureza pública do logradouro não impede, por si, que o Poder Municipal, nos limites de sua competência, permita o fechamento de vias de acesso ou que os moradores contratem segurança privada para o local. 14. Recurso Ordinário não provido. [grifos meus] ${ }^{20}$

\footnotetext{
${ }^{20}$ BRASIL. Superior Tribunal de Justiça. Recurso ordinário em mandado de segurança 2004/0049419-8. PROCESSUAL CIVIL E ADMINISTRATIVO. CONDOMÍNIO. LOGRADOURO PÚBLICO. RECONHECIMENTO. COMPETÊNCIA DA CÂMARA DE VEREADORES. ACÓRDÃO RECORRIDO ADEQUADAMENTE FUNDAMENTADO. LEI MUNICIPAL 3.317/2001. VALIDADE. LEI 6.766/1979. BEM DE USO COMUM DO POVO. RMS 18107. Relator: Ministro Herman Benjamin. Data do julgamento: 25/08/2009. Publicação: 04/05/2011. Disponível em:
} 
Na decisão, percebe-se a confirmação quanto à inaplicabilidade da Lei $n^{\circ} 4.591 / 1964$, § $8^{\circ}$, a casos nos quais as vias internas ao condomínio tenham finalidade diversa da circulação de pedestres e tornam-se verdadeiras vias de trânsito. Ainda, faz-se referência, no caso, à competência municipal para reconhecer logradouros públicos. Fica evidente, durante todo o acórdão, a inadmissão de privatização de espaço que, por suas características, é segmento urbano, submetido ao uso e interesse públicos.

A partir de decisões como esta, corrobora-se a ausência de regularidade no fechamento de bairros localizados em território urbano mantendo privativos serviços cuja utilidade é pública e que afetam o uso dos demais habitantes da mesma cidade. Tem-se o risco de privatização de serviços de interesse coletivo sem qualquer possibilidade de interferência administrativa, causando inclusive novas demandas ao Poder Público. Isso pois esses serviços, quando não prestados da maneira devida, geram violação a direitos fundamentais, e, em último caso, quem deve zelar pela adequada garantia desses direitos é a Administração Pública.

É por ter essa responsabilidade, que a fundo é indelegável, de garantir a dignidade dos cidadãos, que a Administração Pública não pode permitir que haja apropriação das competências públicas pelos particulares; quando isso ocorre, tem o direito de ingerência sobre eles. Nesse sentido, fica claro, na decisão, o direito de o Município reconhecer estes espaços como públicos.

Assim, cabe ao Poder Público municipal assumir a gerência destes espaços encerrados dos condomínios fechados em favor do interesse público. Dessa forma, aplicaria o disposto no Estatuto da Cidade (Lei $\mathrm{n}^{\circ} 10.257 / 2001$ ), tanto em seu art. $1^{\circ}$, que estabelece "o uso da propriedade urbana em prol do bem coletivo, da segurança e do bem-estar dos cidadãos”, quanto nos parágrafos do art. $2^{\circ}$, que determinam diretrizes para a função social do espaço urbano, dentre as quais destacam-se: “[...] garantia do direito a cidades sustentáveis”, “[...] gestão democrática”, “[...] cooperação entre os governos, a iniciativa privada e os demais setores da sociedade no processo de urbanização, em atendimento ao interesse social"21.

Esta arrecadação pela Administração Pública de espaços condominiais que são de uso urbano não precisaria, no entanto, ser realizada de forma absoluta. Se esses espaços surgem

<https://ww2.stj.jus.br/revistaeletronica/ita.asp?registro=200400494198\&dt_publicacao=04/05/2011>. Acesso em: 28 nov. 2011.

${ }^{21}$ BRASIL. Lei $\mathrm{n}^{\circ} 10.257$ de 10 de julho de 2001. Regulamenta os arts. 182 e 183 da Constituição Federal, estabelece diretrizes gerais da política urbana e dá outras providências. In: Diário Oficial da República Federativa do Brasil. Brasília, DF, 2001, 11 jul. 2001. Disponível em: <http://www.presidencia.gov.br/ccivil_03/LEIS/LEIS_2001/L10257.htm>. Acesso em: 1 dez. 2011. 
justamente pela insuficiência do Estado frente às demandas sociais, deve-se considerar que não haverá, instantaneamente, aumento dos recursos públicos no que tange ao suprimento das necessidades. Há que se reconhecer a possibilidade de manter parte da gerência desses espaços sob a coordenação da organização coletiva privada. Fala-se em condomínio misto, de direito público e privado, cuja regulamentação estabeleça diálogo entre a legislação urbanística e a civilista, nas palavras de José Afonso da Silva, um “condomínio urbanístico"22.

A legislação constitucional atribui ao Município a competência para legislação urbanística local ${ }^{23}$, o que dá margem a negociações entre o Poder Público municipal e as incorporadoras que realizam os empreendimentos, em busca de mediação entre o interesse coletivo dos proprietários e o interesse público consubstanciado no plano diretor da cidade.

Nesse sentido, tem-se interessante caso da jurisprudência, a respeito de concessão municipal a condomínio fechado. A medida ocorreu em Itanhaém, São Paulo, que manteve sob o poder dos moradores, ainda que não exclusivo, a prestação de serviços considerados públicos, inclusive segurança. Porém, proibiu que os condôminos impedissem a circulação dos demais cidadãos nas vias interiores do condomínio. Esta condição foi o que causou a discussão na via judicial e acabou chegando a análise em acórdão do STJ, na medida cautelar $n^{\circ} 15.726$ - SP (2009/0124772-0).

$\mathrm{Na}$ ação, os moradores requerem não sejam demolidos muros construídos nos entornos do condomínio. Tem-se o explicativo da posição da associação de moradores do condomínio, citado no relatório, feito pelo ministro Luiz Fux:

(...)A defesa da ré está centrada na Lei Municipal n- 2424, de 29 de dezembro de 1998 (fls 696, 1001 e 1.004) e ainda o "Contrato de Concessão Administrativa de Uso de Bens Públicos Municipais". A lei citada "autoriza a transferência da manutenção, conservação e realização de serviços públicos mediante concessão de uso(...)".

E o seu art. $3^{\circ}$ elenca quais os serviços que, de início, eram prestados pela Municipalidade e que transfere para o particular.

E em seu art. $4^{\circ}$ estabelece que:

"Art 4ํ- A concessionária deverá organizar sistema de vigilância na área do loteamento com o objetivo de preservar os bens e equipamentos públicos,assim como a tranqüilidade e segurança dos moradores, podendo para tanto implantar sistemas de portarias, como portões e/ou cancelas para o controle de acesso, sem prejuízo do poder de polícia dos Poderes Públicos da Federação, União, Estado e Município"

\footnotetext{
${ }^{22}$ SILVA, José Afonso da. Direito urbanístico brasileiro. 4. ed. São Paulo: Malheiros, 2006. p. 351

23 "Art. 30. Compete aos Municípios: I - legislar sobre assuntos de interesse local [...]" BRASIL. Constituição Federal. Brasília: Senado Federal, 1988. Disponível em:
} <http://www.planalto.gov.br/ccivil_03/Constituicao/Constituicao.htm>. Acesso em: 30 jun. 2013 
Todavia, em seu parágrafo 3o prevê que:

"§ 3- - Em nenhuma circunstância será proibido o trânsito de qualquer pessoas na referidas áreas, por continuarem a manter as características de bens de uso comum do povo"

Observe-se, ainda, que o descumprimento desta norma "implicará no cancelamento sumário da presente concessão" (§ $\left.4^{\circ}\right)$.

Ora, o Poder Público autorizou a ré a "(...) implantar sistemas de portarias como portões e/ou cancelas para o controle de acesso" e em seguida fixou que em nenhuma circunstância será proibido o trânsito de qualquer pessoa nas referidas áreas, em face a natureza das vias, isto é, por serem elas "bens de uso comum do povo. ${ }^{24}$ [grifo nosso]

Mesmo nessa terceira opção, verifica-se que prevalece o conflito entre o direito à segurança e o direito à livre circulação. A grande discussão do julgado residia no fato de que a associação de moradores do condomínio fechado não conseguia conciliar seu direito de implementar sistema de cancelas e vigilância com o livre acesso que era imposto pelo Poder Público em troca.

Ponto interessante é que, dentro de proposta como essa, não ficou impedida a edição de norma municipal permitindo o fechamento de determinada área, desde que não entre em conflito com o planejamento urbano do local e não retire completamente o poder administrativo municipal.

A alternativa não elimina a discussão quanto ao fechamento total do acesso à área, que limita os direitos dos cidadãos da localidade. Entretanto, permite que, ao mesmo tempo que os cidadãos possam investir em serviços de qualidade na localidade onde se situam, façam que esses benefícios estejam também à disposição dos cidadãos de seu meio urbano.

Quanto ao conflito relativo ao direito de ir e vir, que traz consigo o direito à socialização dos espaços urbanos, verifica-se que há necessidade de maior diálogo entre Poder Público e cidadãos. Deve-se possibilitar uma gestão conjunta, entre sociedade civil e governo, dos patrimônios da cidade. Nessa ótica, poderia haver incentivo para que os habitantes participassem da gestão dos recursos, na forma de orçamento participativo. Isso colaboraria para que, ao invés de investirem individualmente em espaços privados que atendam seus anseios, construíssem melhores condições para os espaços públicos.

$24 \quad$ BRASIL. Superior Tribunal de Justiça. Recurso especial em medida cautelar 2009/0124772-0. PROCESSUAL CIVIL. ADMINISTRATIVO. MEDIDA CAUTELAR. EFEITO SUSPENSIVO A RECURSO ESPECIAL. ACC̃̃O CIVIL PÚBLICA. LOTEAMENTO TRANSFORMADO EM CONDOMÍNIO FECHADO. LEI MUNICIPAL AUTORIZADORA. CONCESSÃO DE USO. TRANSFERÊNCIA DA MANUTENÇÃO, CONSERVAÇÃO E REALIZACCÃO DE SERVIÇOS PÚBLICOS. CONSTRUÇÃO DE PORTÕES E/OU CANCELAS. LIMITAÇÃO AOS CIDADÃOS. MC 15.726/SP, Relator: Ministro Luiz Fux. Data do julgamento: 20/04/2010 Publicação: 12/05/2010. Disponível em: <https: / / ww2.stj.jus.br/revistaeletronica/Abre_Documento.asp?sLink=ATC\&sSeq=9018288\&sReg=2009012 $47720 \& s$ ata=20100512\&sTipo=91\&formato=PDF>. Acesso em: 30 jun. 2013. 
Falta, nas cidades modernas, a percepção de que o local urbano é composto, além dos espaços onde só um grupo particular tem poder de ingerência, de espaços onde todos devem ter ingerência, e pelo qual consequentemente todos são responsáveis. Somente a partir da concepção de uma gestão urbana que converse com as localidades é que se poderá chegar a essa consciência.

\section{CONCLUSÃO}

Este trabalho discutiu as controvérsias quanto à configuração ou não da natureza jurídica do condomínio fechado, figura que se faz presente no contexto social mas carece de previsão legal.

Apontou-se a formação histórica dos aglomerados urbanos brasileiros, os quais, ao afastarem-se da lógica da interação entre público e privado e renderem-se às fragilidades de nosso sistema econômico, geraram espaços de segregação de classes. Frente a isso, tem-se o fenômeno do medo da violência, em que bairros se enclausuram em busca de liberdade, e o da assunção, por particulares, de serviços atribuídos ao Poder Público.

Esta é a realidade materializada nos condomínios fechados, o que remete a dúvidas quanto à possibilidade de figura com estas características constituir forma legítima e passível de regularização. Demonstrou-se que esta figura está no limbo entre o condomínio edilício e o loteamento, devido à grande área abrangida, à construção de ruas e à presença de áreas comuns. Como observado, a atual legislação utilizada como fundamento para juridicizar esta figura, Lei $n^{\circ} 4.591$, § $8^{\circ}$, não é aplicável a ela. Diferentemente de área na qual é necessário construir vias particulares para acesso à via pública ou para melhor aproveitamento do espaço, o condomínio fechado é forma de parcelamento e ordenamento de grande área territorial.

Levantaram-se as razões para a ausência de legislação, bem como os possíveis conflitos que surgiriam de possível reconhecimento superveniente desta figura pelo legislador. Analisou-se a jurisprudência no tocante ao assunto e observou-se o reconhecimento da competência municipal para leis de matéria urbanística, que envolvem ordenamento do solo. Isso autoriza o Município tanto a reconhecer como de sua alçada a administração das áreas de interesse público 
dentro de um condomínio fechado, mudando sua natureza, como legislar permitindo que tais espaços sejam regularizados como de propriedade privada, alheios à sua administração.

Ficou evidente, pelo exposto, a irregularidade do condomínio fechado nas condições em que este se estabelece. Não há previsão legal e há priorização de interesses de classes mais economicamente favorecidas em detrimento de outras, o que significa desconsideração da função social da propriedade, a qual norteia-se pelo interesse público, e não pelo de determinado segmento social. Não é possível, nestas condições, a regularização do condomínio fechado, muito menos a inércia da Administração Pública frente aos problemas que decorrem desta irregularidade.

Faz-se urgente, desta maneira, a busca por opções que possam ser adotadas pelas administrações municipais, dentre as quais a que é apresentada neste trabalho: a regularização destas áreas, não por meio de legislação que delegue suas funções à iniciativa privada pura, visto que isso desrespeitaria o princípio constitucional da função social dos direitos e a organização das funções do Poder Público, mas uma regularização que estabeleça reorganização de tais espaços de forma a cumprir com esses preceitos.

Ao Poder Público cabe retomar, assim, a gestão do que é de interesse do desenvolvimento urbanístico, conforme the compete por lei, e buscar parcerias entre as coletividades e o gestor público para suprir os déficits nos serviços públicos, fortalecendo a participação popular, dos diversos segmentos da sociedade, na gestão dessas prestações. Poderia haver, nesse âmbito, incentivo para organização de associações de moradores, os quais exerceriam controle social das políticas adotadas e buscariam junto ao gestor público soluções para a melhoria de qualidade dos serviços prestados à sua localidade urbana.

Conclui-se pela necessidade de regulamentação para administração mista dessas áreas atualmente privadas, nas quais o Município estabeleça diálogo com os seus habitantes e retome a publicidade das áreas comuns urbanas (como ruas e iluminação), responsabilizando-se por sua manutenção e dando a elas função social dentro das cidades. Assim, entende-se que o condomínio fechado, uma vez tornando-se aberto ao acesso de todos os cidadãos e à gestão conjunta de moradores e Poder Público, pode vir a simbolizar o equilíbrio entre espaços públicos e privados, essencial à organização urbana. 


\section{REFERÊNCIAS}

ARANTES, Rafael de Aguiar. Qualidade de vida ou fortificações: o significado dos condomínios fechados em Salvador. In: Revista Veracidade, ano IV, $\mathrm{n}^{\circ}$ 4, março de 2009. Disponível em: <http://www.veracidade.salvador.ba.gov.br/v4/images/pdf/artigo3.pdf>. Acesso em: 27 nov. 2011.

BRASIL. Constituição Federal. Brasília: Senado Federal, 1988. Disponível em: <http://www.planalto.gov.br/ccivil_03/Constituicao/Constituicao.htm>. Acesso em: 30 jun. 2013.

BRASIL. Lei $n^{\circ} 4.591$ de 16 de dezembro de 1964. Dispõe sobre o condomínio em edificações e as incorporações imobiliárias. In: Diário Oficial da República Federativa do Brasil. Brasília, DF, 21 dez. 1964. Disponível em: <http://www010.dataprev.gov.br/sislex/paginas/42/1964/4591.htm>. Acesso em 30 jun. 2013.

BRASIL. Lei $n^{\circ} 10.257$ de 10 de julho de 2001. Regulamenta os arts. 182 e 183 da Constituição Federal, estabelece diretrizes gerais da política urbana e dá outras providências. In: Diário Oficial da República Federativa do Brasil. Brasília, DF, 2001, 11 jul. 2001. Disponível em: <http://www.presidencia.gov.br/ccivil_03/LEIS/LEIS_2001/L10257.htm>. Acesso em: 30 jun. 2013.

BRASIL. Lei $\mathrm{n}^{\circ} 10.406$ de 10 de janeiro de 2002. Institui o Código Civil. In: Diário Oficial da República Federativa do Brasil. Brasília, DF, 11 jan. 2002. Disponível em:

<http://www.planalto.gov.br/ccivil_03/leis/2002/L10406.htm>. Acesso em: 30 jun. 2013.

BRASIL. Superior Tribunal de Justiça. Recurso ordinário em mandado de segurança 2004/0049419-8. PROCESSUAL CIVIL E ADMINISTRATIVO. CONDOMÍNIO. LOGRADOURO PÚBLICO. RECONHECIMENTO. COMPETÊNCIA DA CÂMARA DE VEREADORES. ACÓRDÃO RECORRIDO ADEQUADAMENTE FUNDAMENTADO. LEI MUNICIPAL 3.317/2001. VALIDADE. LEI 6.766/1979. BEM DE USO COMUM DO POVO. RMS 18107. Relator: Ministro Herman Benjamin. Data do julgamento: 25/08/2009. Publicação: 04/05/2011. Disponível em:

<https: / /ww2.stj.jus.br/revistaeletronica/ita.asp?registro=200400494198\&dt_publicacao=04/05/ 2011>. Acesso em: 28 nov. 2011.

BRASIL. Superior Tribunal de Justiça. Recurso especial em medida cautelar 2009/0124772-0. PROCESSUAL CIVIL. ADMINISTRATIVO. MEDIDA CAUTELAR. EFEITO SUSPENSIVO A RECURSO ESPECIAL. AÇÃO CIVIL PÚBLICA. LOTEAMENTO TRANSFORMADO EM CONDOMÍNIO FECHADO. LEI MUNICIPAL AUTORIZADORA. CONCESSÃO DE USO. TRANSFERÊNCIA DA MANUTENÇÃO, CONSERVAÇÃO E REALIZAÇÃO DE SERVIÇOS PÚBLICOS. CONSTRUÇÃO DE PORTÕES E/OU CANCELAS. LIMITAÇÃO AOS CIDADÃOS. MC 15.726/SP, Relator: Ministro Luiz Fux. Data do julgamento: 20/04/2010 Publicação: 12/05/2010. Disponível em:

<https: //ww2.stj.jus.br/revistaeletronica/Abre_Documento.aspsLink=ATC\&sSeq=9018288\&sReg= $200901247720 \& s D a t a=20100512 \& s T i p o=91 \&$ formato=PDF>. Acesso em: 30 jun. 2013.

COULANGES, Fustel de. A cidade antiga. São Paulo: Martin Claret, 2002. 
ISSN 1981-3694

(DOI): $10.5902 / 198136949314$

REVISTA ELETRÔNICA DO CURSD DE

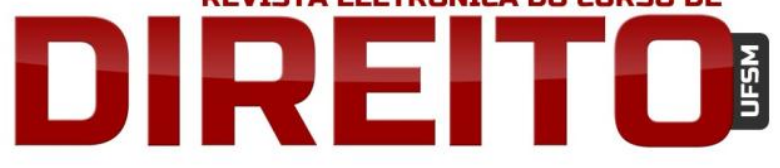

A POSSÍVEL (?) NATUREZA JURÍDICA DO CONDOMÍNIO FECHADO: diálogo entre Direito das Coisas e Direito Urbanístico

Lahis Pasquali Kurtz

IBGE, IBGE teen. Características da população. Disponível em:

<http://www.ibge.gov.br/ibgeteen/pesquisas/demograficas.html>. Acesso em: 28 nov. 2011.

MUKAI, Toshio. Temas atuais de direito urbanístico e ambiental. Belo Horizonte: Fórum, 2004.

RIZZARDO, Arnaldo. Direito das coisas: Lei $n^{\circ} 10.406$, de 10.01.2002. 2. ed. Rio de Janeiro:

Forense, 2006.

SILVA, José Afonso da. Direito urbanístico brasileiro. 4. ed. São Paulo: Malheiros, 2006.

Recebido em: 13.07.2013

Correções em: 04.12.2013

Aprovado em: 05.12.2013 